\title{
The Study of Persian Address Terms in Young Adult Novels According to the Politeness Theory
}

\author{
Nooshin Azin \\ Department of Language, College of Humanities, Islamshahr Islamic Azad University \\ azin@iiau.ac.ir
}

\author{
Akbar Afghari \\ Department of Language, Khorasgan Islamic Azad University
}

Doi:10.5901/mjss.2015.v6n5s1p438

\section{Abstract}

This study attempts to analyze Persian address terms on the basis of the politeness theory in young adult novels in two distinctive periods of Pahlavi (1926-1979) or Before Islamic Revolution (BR) and after the Islamic Revolution (1979 -up to now) $(A R)$. For this purpose, 8 young adult novels were selected, 4 from $B R$ and 4 from AR. Then 326 address terms were identified and classified by types. Data analysis showed that in both $B R$ and $A R$, positive address terms are used more than negative ones. The results of the study demonstrated that the frequency of some address terms has changed; however, the variation in frequency is not significant. Thus, it can be concluded that since one of the essential objectives of young adult literature is the development of healthy youth in healthy communities through instructive and edifying literature, it is not affected by sociopolitical and sociocultural changes.

Keywords: Persian address terms, Negative and positive politeness, Young adult novel, After Islamic revolution, Before Islamic revolution.

\section{Introduction}

Language is not merely for exchanging knowledge and information; it shows individuals' relationships, identities, culture and preferences to become close or distant from others.

How people open and end conversation, how they address one another in a given context are significant in studying communication. Address terms are never neutral in communication. They are believed to convey feelings and attitudes; the choice of these elements is based on interlocutors' evaluation of communication situation.

Afful believes (2006a) "terms of address constitute an important part of verbal behavior through which the behavior, norms and practices of a society can be identified". The study of address terms can be regarded as a valuable field for sociolinguistics since it displays the construction of interpersonal interactions from social and strategic point of view (Fitch 1991, Morford 1997). To Philipsen and Huspek (1985: 94) "terms of address reflect the social and linguistic background of interactants to a greater extent than other aspects of language",

This is one of the key reasons for widespread studying of address terms among sociolinguists.

Brown and Levinson (1987:126) state that address terms are essential linguistic devices which reflect interlocutors' attitude and their evaluation of addressee in interaction. Using proper address terms would lead to individuals' identification of themselves as a member of a social group whereas choosing improper terms stops communication. According to Akindele (2008) these linguistic terms reveal interlocutors' social status along with their social distance, moreover these terms show people's emotion toward another speaker.

Many sociolinguists all around the world have focused their attention on analyzing address terms since they represent interpersonal relationships and the level of politeness in a certain society.

\subsection{Address terms}

"Address terms" are identifiable in all languages of the world .To Braun (1988: 7), their function is basically "initiating contact." He adds that the literal and lexical meanings of address terms sometimes do not show the addressee's true relations. Maybe in Iran and some Arab countries, though there is no blood relation between interlocutors, one boy might call his friend's father as "uncle" to display closeness.

Afful (2006b) defines terms of address as the linguistic elements that a presenter entitles a recipient in a direct 
situation. Keshavarz (2001: 6) believes that address terms refer to "...linguistic forms that are used in addressing others to attract their attention or for referring to them in the course of a conversation." Dickey's (1996) made further divisions. He classifies address terms to pronouns, verbs and nouns and then categorized them as 'bound' and 'free' forms.

Address terms have social functions as well. According to Murphy (1988) these terms are socially driven phenomena. This characteristic of address terms can obviously reflect the intricate social relations among people (Paulston1976, Trudgill 1983, Chaika1982). These terms stem from socio-cultural setting of a speech community. To Leech (1999) address terms are "important formulaic verbal behaviors well recognized in the sociolinguistics literature to signal transactional, interpersonal and deictic ramifications in human relationships." It is believed that the behavior, norms and customs of a community can be recognized through studying its address terms.

Likewise, Parkinson (1985: 1) affirms that address terms can disclose essential social information. He adds that the form of an expression "encode much information about who the speaker believes he is, who he believes the addressee is, what he thinks their relationship is, and what he thinks he is doing by saying what he is saying."

\subsection{Classification of Persian address terms}

Different languages have different classifications for their address terms. Many studies have been done to categorize them in different languages, such as: Hindi by Mehrotra (1981), Egyptian Arabic by Parkinson (1985), Columbia by Fitch (1998), Kannada (one Indian language) by Manjulakshi (2004), and Ghana by Afful (2006a).In Persian language, according to Aliakbari and Toni (2008) address terms can be classified as follow: "personal names, general titles, occupation titles, kinship related terms, religious oriented expressions, honorifics, terms of intimacy, personal pronouns, descriptive phrases and zero-address terms."

Teknonyms are added in this analysis since they are frequently used in Persian language. Moreover, descriptive phrases are not considered as a separate type of address terms since each type can be stated in a descriptive form.

Each type will be explained briefly based on Aliakbari and Toni (2008) classification with related examples which marked by quotation mark:

(1) Personal names: refer to first name, e.g., حسين /Hossein/, last name, e.g., اكبرى /Akbaril, or combination of them such as, حسين اكبرى/Hossein Akbaril.

(2) General titles: refer to initials that display social status and gender in different situations, terms like: اسد آنا /Asad âghâ/ (Mr. Asad), مينا خانم /Mina khânom/ (Mrs. Mina)."

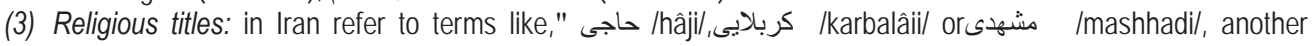

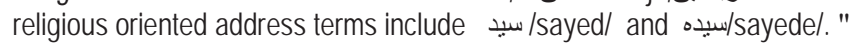

(4) Occupational titles: One can be called" مهندس /mohandes/ (engineer), دكتر /doktor/ (doctor), based on his/her occupation and using these titles are very common in Persian language."

(5) Terms of formality or honorifics: these terms are employed to show respect for the addressees. Some of them are as follow:" قربان /ghorbân/ (sir), سناب /jenâb/ (sir) and سركار/sarkâr/ (lady)."

(6) Terms of intimacy: by using these terms, we want to show our closeness and intimacy to our addressees. Some examples are: nicknames, e.g., فرى /Feril (used for Fereydoon), "abbreviated first name e.g., ممد /Mamad/ (used for Mohammad), pet names, e.g., عزيزم /azizam/ (my dear), خانم خانما /golam/ (my flower), خلم /khânom khânoma/ (lady of ladies)."

(7) Personal pronouns: In Persian language it is possible to show solidarity or power by using personal pronouns. The addressee can be called as" تو /towl (second person singular 'you') or Lما/Shomâl (second person plural 'you').For showing respect, the plural you is used for a singular person. Likewise, Persian speakers may use او loo/ or ايشان /ishân/ to talk about the third person, but ايشان /ishân/shows much respect."

(8) Kinship or Family/Relative Terms: Numerous Persian address terms are used to identify the family relations.

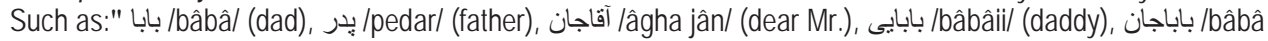

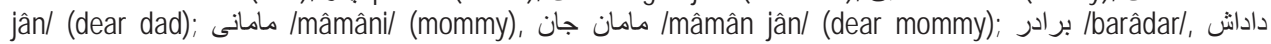

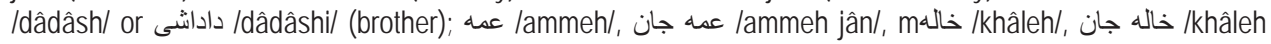
jân/, (aunt). "

(9) Zero address terms: For opening" a polite conversation, addressers may use these expressions to attract addressees' attention: ببخشيد /bebakhshid/ (excuse me), or معذرت مى خوام /mazerat mikhâm/ (pardon me), or greetings like سلام/salâm/ (hello) or صبح بخير/sobh bekheyr/ (good morning)."

(10) Teknonyms: These terms are not included in Aliakbari and Toni's classification. Here the addressees are called and identified through their relation to someone else, for example خانم آقاى كريمى khânome âghâye Karimil/ (Mr.Karimi's wife), خانم دكتر/khânome doctor/(Mr.doctor's wife). 


\subsection{Politeness theory}

Politeness implies considering others' feelings and selecting terminologies appropriately to make others feel relaxed and comfortable. Since it is a culturally defined phenomenon, what is believed polite in one culture may sometimes be completely impolite or weird in another cultural context.

Anthropologists Penelope Brown and Stephen Levinson (1987), based on Erving Goffman's notion of face, proposed politeness theory and recognized two kinds of politeness. They believe address terms can display either positive or negative politeness.

According to Brown and Levinson (1987) politeness in a communication is "the means employed to show awareness of another person's face or 'face want' of addressee, which is highly valued in conversation." It could be ignored, preserved or emphasized. During our communication, "we are constantly aware of our own and others' face needs, we attend to it consciously or unconsciously, and we cooperate to maintain one another's face." We use a range of strategies to show our politeness as well as terms of address to make softer our utterances and consider the other's face needs.

\subsection{Purpose of the study}

The main objective of this study is to analyze address terms in Persian language in young adult novels based on politeness theory in two distinctive eras of Pahlavi (1926-1979)or Before Islamic Revolution (BR) and After the Islamic Revolution (1979 -up to now) or (AR).

Therefore, the main research questions are as follow:

1. What is the distribution of address terms in Persian language based on the theory of politeness in young adult novels?

2. Is there any variation in frequency of the Persian address terms based on the theory of politeness in these two historical periods in young adult novels?

\section{Literature Review}

A number of studies in this area based on politeness theory have been done:

In their study of English address terms, Wood and Kroger (1991) found that negative terms of politeness exceed positive ones; besides it was stated that negative politeness terms show more respect.

In a study of Japanese honorifics, Fukada and Asato (2004) concluded that the usage of honorifics is in accordance with the Brown and Levinson's theory of politeness.

Concentrating on the socio-pragmatic features of address terms in late 16th-century English notes, Nevala (2004) indicated that the causes for selecting proper politeness terms (positive or negative) are intricate, and the boundaries prepared for them cannot be usable in the same way.

Iragiliati (2006) studied address terms of medical discourse in Indonesia. The findings illustrated that positive politeness is attained through using kinship terms of Indonesian type such as 'sister', 'brother' and 'aunt' whereas negative politeness is attained by using impersonal address terms like 'title' or 'family name'.

Likewise, several analyses have been performed on address terms in Persian language:

In his study, Keshavarz $(1988,1993)$ found that since the 1979 Iranian revolution, address terms that show solidarity and simple kind of speech have been more widespread. In another study, he examined the effect of distance, intimacy and social context on Persian address forms and pronominal selection. He concluded that there is a negative relation between formality of context and using intimate address terms (Keshavarz 2001).

Akbari (2002) tried to classify, compare and contrast politeness strategies of Persian mono-lingual speakers in particular conditions with those employed in English.

Focusing on how address forms mirror solidarity and power relationships, Afzali (2011) examined various forms that partners (husbands \& wives) use to address each other in different social positions.

Dadmehr and Sharifi Moghaddam (2014) investigated differences and similarities between terms of address used in Farsi and English. The results of their research disclosed that generally the positive politeness terms were used more frequently than the negative politeness terms in both languages. However, the negative address terms were more common in Farsi than in English.

Sharifi Moghaddam, Yazdan Panah and Abolhassanizadeh (2013) examined Persian terms of address in the three distinctive era of Qajar, Pahlavi and after the Islamic Revolution based on the politeness theory. They concluded that the 
entire positive address terms increased in number and a gradual movement from formality to solidarity can be seen.

Although numerous studies have been carried out to analyze forms of address in Persian, none of them investigated the use of these forms in young adult literature within the theory of politeness; thus, it would be instructive to shed some light on this issue.

\section{Method}

\subsection{Theoretical framework}

According to Keshavarz (2001) many researchers in the field of sociolinguistics, believe that address terms evidently show the relationship between language and society. These terms can represent politeness in speaking as well as writing.

Brown and Levinson (1987) state that identification of positive and negative politeness is fundamental to politeness theory, and addressing terms can show both, for instance, positive terms like first name or nicknames can be used to show solidarity and closeness, while negative terms like last name, titles and honorifics aim at showing respect and distance. Address terms are considered as the most direct means for expressing positive and negative politeness in this system.

In this study, politeness theory of Brown and Levinson enables us to analyze variation and distribution of Persian address terms in young adult novels before and after 1979 revolution.

\subsection{Collection of data}

8 young adult novels were randomly selected from the most published books, 4 from BR and 4 from AR. These novels were considered as the corpus for studying address terms in the two distinct historical periods. Then from these 8 novels, 326 terms of address were derived and classified.

"Young adulthood" often described as developmental and unique stage which is distinguished by unique needs. Considering these needs, young adult literature is considered valuable both from its artistic point of view and its significance to the readers' lives. Young adult literature is generally written for young readers aged approximately between12 to 18 .

Novels were chosen for this study among different types of literature because of these reasons:

First, novels especially their conversation parts seem closer to the common language used in a society which is less formal and figurative; consequently, they can mirror cultural, social and moral values of a community.

Second, due to inadequate documented records from the past to present, conversations in novels were studied as the best proximate alternatives.

The novels used in this study are presented in the Appendix. Due to fundamental changes in socio-cultural and political situations because of Islamic revolution, the periods under study are considered as two distinct historical stages. Thus a brief overview of these periods seems useful.

Pahlavi period (BR): the Pahlavi gained control after Qajar dynasty. Pahlavi Empire reigned over Persia (Iran) from 1305-1357 (1926 -1979). The empire had two kings, Reza Pahlavi and Mohammad Reza Pahlavi, father and son.

Islamic Revolution (AR): under the leadership of Ayatollah Khomeini, the Islamic revolution leads to overthrowing of the Pahlavi kingdom. According to Arjomand (1988) the 1979 revolution may be considered as a revolutionary class movement, a shift from technocrat (elite) ruling class to traditional (religious) class.

\section{Data Analysis}

The data included 326 Persian address terms which were extracted from 8 novels in two historical periods. Then they are analyzed based on the politeness theory. $130(p=40 \%)$ terms are related to BR and $196(p=60 \%)$ to AR. The main objective of this section is to display the distribution and frequency variation of Persian address terms according to the politeness theory.

Thus, these 326 Persian addressing expressions from BR and AR were examined to find out whether they can be categorized into positive and negative types. After analyzing of the data, it was revealed that Persian address terms can be categorized into positive and negative types. 


\subsection{Positive and negative address terms}

Positive terms of address which stress close relationship with interlocutors are as follow: personal names, kinship terms, and terms of intimacy.

On the other hand, Negative address terms which avoid face-threatening acts can be classified as: general titles, religious titles, occupational titles, honorifics, personal pronouns, zero addresses terms, and teknonyms.

In this study, personal pronoun/ شما /shomâl (plural 'you') that used for a singular person is considered as a negative politeness term since it shows distance and respect, and تو /Tow/ (singular 'you') as positive since it displays closeness and intimacy.

\subsection{Frequency of positive and negative address terms in $B R$ and $A R$}

The frequency of some address terms have been changed. As displayed in Table and Graph 1, in positive types; the usage of personal terms have risen while, the employment of kinship and intimacy terms have shown to decrease from BR to AR:

Table 1: Positive terms from BR to AR

\begin{tabular}{|l|c|c|}
\hline & BR & AR \\
\hline Personal Names & $\% 28.26$ & $\% 58$ \\
\hline Kinship Terms & $\% 36.95$ & $\% 30$ \\
\hline Intimacy Terms & $\% 34.78$ & $\% 12.31$ \\
\hline
\end{tabular}

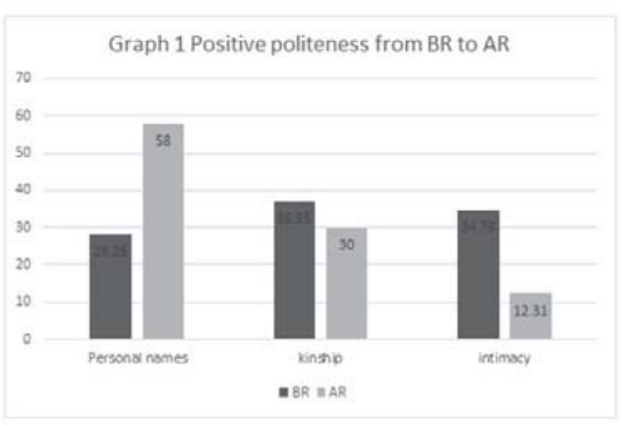

From negative categories; general titles, honorifics, and zero address forms have decreased as shown in Table and Graph 2.

Table 2: Negative terms from BR to AR

\begin{tabular}{|l|c|c|}
\hline & BR & AR \\
\hline General Title & $\% 76.31$ & $\% 31$ \\
\hline Honorifics & $\% 5.26$ & $\% 3.44$ \\
\hline Zero Addresses Terms & $\% 2.63$ & $\% 0$ \\
\hline
\end{tabular}

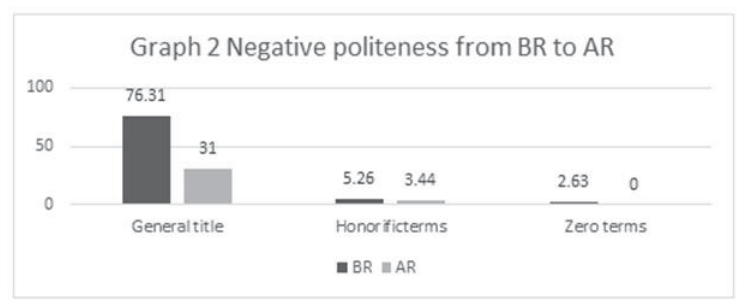


However, religious titles, occupational titles, personal pronouns, and teknonyms have increased in number as presented in Table and Graph 3.

Table 3: Negative politeness from BR to AR

\begin{tabular}{|l|c|c|}
\hline & BR & AR \\
\hline Religious Titles & $\% 0$ & $\% 8.6$ \\
\hline Occupational Titles & $\% 2.63$ & $\% 5.17$ \\
\hline Personal Pronouns & $\% 10.52$ & $\% 36.2$ \\
\hline Teknonyms & $\% 2.63$ & $\% 15.5$ \\
\hline
\end{tabular}

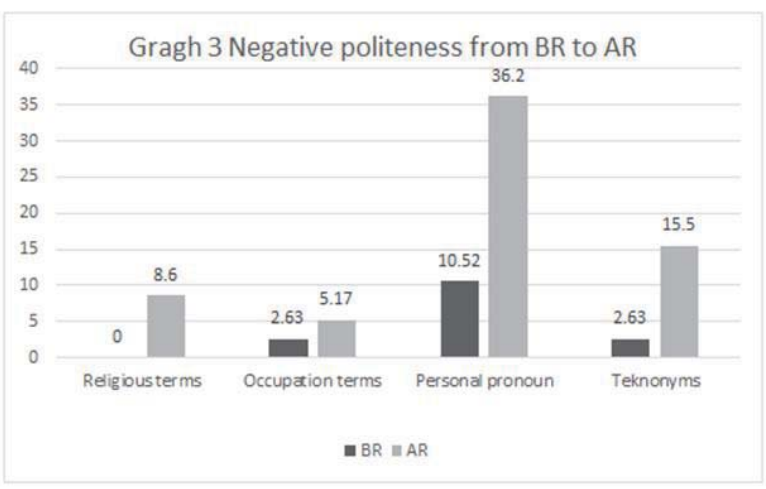

The analysis of the entire positive and negative address terms reveals no significant changing from BR to AR in young adult novels.

As it can be seen in Graph 4, in both BR and AR, positive terms of address are used more than the negative terms: $70.76 \%$ in $\mathrm{BR}$ and, $70.67 \%$ in AR.

This result is in contrast with Moghadam et al. (2013) conclusion which showed negative politeness terms used more than positive politeness in 3 historical periods. Moreover, dissimilar to their report on increasing trend of positive terms in adults novels from $6 \%$ in Qajar to $34 \%$ in Pahlavi (BR) and then to $42 \%$ after Islamic revolution (AR), the present study does not show any significant changing direction of politeness types from BR to AR.

Table 4: Politeness types in two historical periods

\begin{tabular}{|c|c|c|}
\hline & Positive & Negative \\
\hline BR & 70.76 & 29.08 \\
\hline AR & 70.67 & 29.55 \\
\hline
\end{tabular}

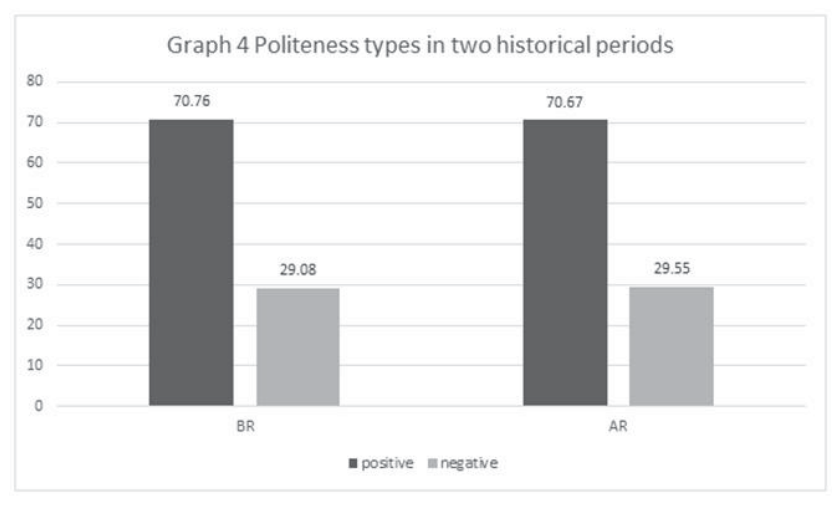




\section{Conclusions and Discussion}

As it was mentioned, 326 Persian address terms from 8 young adult novels in the two historical periods ( $A R$ and $B R$ ) were collected and analyzed on the basis of the politeness theory. After analyzing these terms, the following results obtained:

In $B R$ and $A R$, address terms of Persian could be grouped into positive and negative kinds.

In both $B R$ and $A R$, positive address terms are used more than the negative terms.

It is generally believed that address terms reveal social changes; however, this set does not show any significant variations during these two periods.

For discussing possible reasons, first it seems useful to define "young adulthood" which often described as developmental period. According to Michael Cart (2008) "Young adults are beings in evolution, in search of self and identity; beings who are constantly growing and changing, changing from the condition of childhood to that of adulthood. ... Young adulthood is a unique part of life".

Consequently, young adult literature can be considered significant by both its artistic quality and its importance to developmental needs of the readers. It acts as "a factor promoting positive teenage development."

To YALSA (Young Adult Library Services Association) one of the foremost merits of young adult literature is its ability to reflect the readers' life in its pages and reassuring that one is not alone. The other value of young adult literature is its capability in developing perception, sympathy and humanity. Yet another benefit of young adult literature is its potential role to tell its readers the truth, though displeasing it can be. Moreover, it can expose a model to the youngsters so that they can shape their philosophy of being. They can decide what is right and wrong to become civilized and responsible.

Considering the above mentioned points, it can be concluded that since one of the essential objectives of young adult literature is development of healthy youth in healthy communities through instructive, informative, and edifying works, it is less affected by sociocultural and sociopolitical changes.

Finally it should be mentioned that, AR novels used in this study published between 1982 to 2001 (1361-1380); thus it seems necessary to conduct another research for exploring more current young adult literature to observe the possible influence of social changes as well as social networks on address terms.

\section{References}

Afful, J. B. A. (2006a). Address terms among university students in Ghana. A case study. In Journal of language and intercultural communication, 2006, vol. 6, no. 1, pp.76-91.

Afful, J. B. A. (2006b). Non-kinship address terms in Akan. A sociolinguistic study of language use in Ghana. In Journal of multilingual and multicultural development, 2006, vol. 27, no. 4, pp.275289.

Afzali, K. (2011). The role of address forms of spouses in different social strata in Iran and its sociolinguistic implications. In International journal of linguistics, 2011, vol. 15, no. 1, pp.82-86.

Akbari, Z. (2002). The Realization of Politeness Principles in Persian. Karen's Linguistics Issues, May 2002. www3.telus.net/linguistics issues/persian.pdf.

Akindele, D.F. (2008). Sesotho address forms. In Linguistik online, 2008, vol. 34, no. 2, pp. 3-15.

Aliakbari, M. \& Toni, A. (2008). The realization of address terms in modern Persian in Iran: A socio-linguistic study. In Linguistik online, 2008, vol. 35, no. 3, pp. 3-12.

Arjomand, S. A. (1981). Shi'ite Islam and the Revolution in Iran. Government and Opposition onlinelibrary.wiley.com > ... > Vol 16 Issue 3.

Braun, F. (1988). Terms of address: Problems of patterns and usage in various languages and cultures. New York: Mouton de Gruyter, 1988.

Brown, P. \& Levinson, S. C. (1987). Politeness: Some universals in language usage. Cambridge: Cambridge University Press, 1987.

Chaika, E. (1982). Language the social mirror. Rowley, MA: Newbury House, 1982.

Cart, M. (2008). The value of young adult literature. Available at: www.yalsa.ala.org.

Dadmehr, S. \& Sharifi Moghaddam, A.(2014). A Contrastive Analysis of Address Terms in Farsi and English (Based on Theory of Politeness).International Journal of Basic Sciences \& Applied Research. Vol., 3 (SP), 16-24, 2014. Available online at http://www.isicenter.org ISSN 2147-3749 @2014

Dicey, E. (1996). Forms of address and terms of reference. In Journal of linguistics, 1996, vol. 33, pp. 255-274.

Fitch, K. L. (1998). Speaking relationally: culture, communication, and interpersonal connection. New York: Guilford, 1998.

Fukada, A. \& Asato, N. (2004). Universal politeness theory: application to the use of Japanese honorifics. In Journal of pragmatics, 2004, vol. 36, pp. 1991-2002.

Holms, J. (1992). An introduction to sociolinguistics. London: Longman, 1992.

Iragiliati, E. (2006). Politeness, forms of address and communicative codes in Indonesian medical discourse. In Bahasa dan seni, 2006, vol. 34, no. 1, pp. 19-36. 
Keshavarz, M. H. (1988). Forms of address in post-revolutionary Iranian Persian: A sociolinguistic analysis. In Language in society, 1988, vol. 17, pp. 565-575.

Keshavarz, M. H. (1372/1993). Zamaer-e shakhsi va sorathay-e khetab (personal pronoun and forms of address). In Farsi journal, vol. 1, no. 74 , pp. $71-84$.

Keshavarz, M. H. (2001). The role of social context, intimacy, and distance in the choice of forms of address. In International journal of society and language, 2001, vol. 148, pp. 5-18.

Leech, G. (1999). The distribution and function of vocatives in American and British English conversation. In HASSELGARD, Hilde, OKSEFJELL, Signe (eds.), Out of corpora. Studies in honor of Stig Johansson. Amsterdam: John Benjamins, 1999, pp. 107-118.

Manjulakshi, L. (2004). Modes of address in Kannada: A sociolinguistic study of language use in Mysore District. Available at: <http://www.languageinindia.com/sep2004/ manjulakshitermsofaddress1.html (accessed September 2008) >.

Mehrotra, R. R. (1981). Non-kin forms of address in Hindi. In International journal of the sociology of language, 1981, vol. 32, pp. 121137.

Morford, J. (1997): "Social indexicality in French pronominal address". Journal of Linguistic Anthropology 7: 3-37.

Murphy, G. L. (1988). Personal reference in English. In Language in society, 1988, vol. 17, pp. 317-349.

Nevala, M.( 2004). Inside and out. Forms of address in seventeenth- and eighteenth-century letters. In Journal of historical pragmatics, 2004, vol. 5, no. 2, pp. 271-296.

Parkinson, D. B. (1985). Constructing the social context of communication: Terms of address in Egyptian Arabic. Berlin: Berlin University Press, 1985.

Paulston, C. B. (1976). Pronouns of address in Swedish: social class semantics and a changing system. In Language in society, 1976, vol. 5, pp. 359-386.

Phlipsen, G. \& Huspeck, M. (1985). A bibliography of sociolinguistic studies of personal address. In Anthropological linguistics, 1985, vol. 27, no. 1, pp. 94-101

Sharifi Moghadam, A. et al. (2013). The Analysis of Persian Address Terms Based on the Theory of Politeness. In SKASE Journal of Theoretical Linguistics [online]. 2013, vol. 10, no.3 [cit. 2013-06-18].

Trudgill, P. (1983). Sociolinguistics: An introduction to language and society. Harmondsworth: Penguin, 1983.

Wood, L. A. \& Kroger, R. O. (1991). Politeness and forms of address. In Journal of language and social psychology, 1991, vol. 1, no. 10, pp. 145-168.

\section{Appendix}

\section{A) Before Revolution (BR) novels:}

Behrangi,S. (1965/1344). Oldooz va kalagh ha( Oldooz and the Crows).Tehran: Afrasiab publication.

Darvishian, A. (1975/1353). Rangineh. Tehran: Negah publication.

Khaksar, N. (1975/1353).Man midanam bache ha doost darand bahar biyayad( I know that children like spring).Tehran: Nima Publication.

Yaghooti,M.(1979/1358).Ba bache haye dehe khodeman (With our villagers). Tehran: Peyvand publication.

\section{B) After Revolution (AR) novels:}

Bani Ameri, H. (2001/1380).Babaye ahooye man bash. (Be father of my deer)Tehran: Payizan publication. Bayrami, M. (1992/1371). Shab dar biaban (Night in the desert). Tehran: Hoze Honari publication. Ghaffarzadegan, D. (1992/1371).Zemestan dar rah( Winter is coming) Tehran: Hoze Honari publication.

Rahgozar, R. (1982/1361).Anja ke khane am nist(Where there isn't my home) Tehran: Institute for the Intellectual Development of children and Young adult. 